\title{
Endoscopic transnasal external fistulation in recurrent cystic subdiaphragmatic craniopharyngioma: a novel technique
}

\author{
Sandeep P. Solanki, FRCS, ${ }^{1}$ Anshul Sama, FRCS $^{2}$ and lain J. Robertson, FRCS ${ }^{1}$ \\ Departments of ${ }^{1}$ Neurosurgery and ${ }^{2}$ Otorhinolaryngology-Head and Neck Surgery, Queen's Medical Centre, Nottingham, \\ England
}

\begin{abstract}
The authors present a technique for the persistent external drainage of intractable subdiaphragmatic cystic recurrences with the creation of a fistula between the cyst wall epithelium and epithelium on the nasal cavity, using a pedicled nasoseptal flap as a conduit. The long-term efficacy of endoscopic transnasal external fistulation (ETEF) in controlling cystic recurrences in this patient group is addressed through a retrospective observational review of 3 male patients aged 8 , 22, and 45 years with the diagnosis of recurrent cystic subdiaphragmatic craniopharyngioma who underwent the ETEF procedure between 2006 and 2009. Clinical presentation, neuroimaging, surgical interventions, and follow-up were recorded. The main outcome measure was cyst reaccumulation on MRI.

Patients had a mean follow-up of 76 months (range 5-8 years) with no incidence of cystic recurrence. Follow-up imaging revealed sustained cyst involution contrary to the usual recurrent enlargement commonly seen in this patient group. Symptoms of headache and visual field defects improved post-ETEF. Long-term theoretical complications of a persistent fistula such as intracranial abscess, meningitis, or CSF leak were not observed. ETEF promotes nasalization of cystic recurrences in subdiaphragmatic craniopharyngioma. It is safe and effective, causing long-term involution of cysts and can be considered a definitive procedure.
\end{abstract}

http://thejns.org/doi/abs/10.3171/2015.6.PEDS14520

KEY WORDS craniopharyngioma; ETEF; endoscopic transsphenoidal; nasoseptal flap; skull base surgery; oncology

$\mathrm{C}$ RANIOPHARYNGIOMAS are tumors that arise due to embryogenic malformations in the sellar region and comprise $1 \%-4 \%$ of all brain tumors. ${ }^{22}$ Two main theories exist to explain these anomalies; the first suggests that craniopharyngioma originates from the embryonic remnants of Rathke's pouch. The second proposes that such tumors arise from squamous cells of the par tuberalis of the pituitary gland. Indeed, the main pathologic subtypes of craniopharyngioma - adamantinomatous and squamous-papillary - may reflect the 2 respective hypotheses. ${ }^{21}$

The incidence of adamantinomatous craniopharyngioma has a bimodal distribution, with peaks being in childhood and also in adulthood, in contrast to the squamouspapillary subtype that is limited to adulthood..$^{17,25}$ These lesions may be cystic, solid, or mixed in nature. Ninety percent of the adamantinomatous subtype and $50 \%$ of the squamous-papillary types are found to be cystic. ${ }^{1}$

The clinical significance of such midline tumors is that they exert mass effect, with patients presenting with visual and cognitive impairment, endocrinopathy, and symptoms of raised intracranial pressure. ${ }^{17}$

Historically, the management of craniopharyngioma has been challenging, as achieving successful, curative, gross-total resection of this lesion is rather difficult due to its proximity or adherence to surrounding critical neurovascular structures. ${ }^{2,4}$

Tumor and cystic recurrence is hence attributed to incomplete or subtotal resection, and thus rates of recurrence can be reduced with gross-total resection but at the cost of increased morbidity. 2,20,26 Therefore, a widely accepted strategy in management of craniopharyngioma is a safe resection, which is as near total as possible without causing detriment by means of damage to critical neurovascular structures. Thereafter, adjuvant therapy such as radiotherapy may well be considered to augment the effects of a safe resection, which can be as effective as gross-total resection alone. ${ }^{6}$

ABBREVIATIONS DI = diabetes insipidus; $E T E F=$ endoscopic transnasal external fistulation 
Despite this, recurrence is common: as high as 50\% in some series, ${ }^{19}$ and usually within $2-5$ years of resection, ${ }^{25}$ but also reported after 30 years. ${ }^{12}$ There are a multitude of strategies directed at recurrence, the choice of which are influenced by cystic or solid predominance.

Strategies addressing recurrence include re-resection or cyst drainage via the transcranial or transsphenoidal routes ${ }^{23}$ fractionated radiotherapy; ${ }^{17}$ Gamma Knife ${ }^{18}$ and CyberKnife ${ }^{14}$ stereotactic radiosurgery; and insertion of an intracystic Ommaya reservoir for repeated aspiration ${ }^{16}$ or administration of chemotherapy (bleomycin and interferon alpha). ${ }^{7}$ Although such strategies have been shown to be effective, they are not always definitive in addressing recurrence.

Our particular interest is that of recurrent cystic subdiaphragmatic craniopharyngioma. In light of the difficulty in achieving complete resection of the craniopharyngioma epithelium, our aims were to devise a persistent drainage pathway for cyst fluid in the context of recurrent cystic craniopharyngioma. This would provide a permanent drainage solution, thus preventing cystic reaccumulation and repeated surgery. Our technique would circumvent the need to completely excise the cyst epithelium, which can be risky, by providing a drainage pathway for the fluid continuously produced by the epithelium.

To create a permanent drainage pathway into which cystic fluid would be allowed to drain required the selection of an appropriate route. Given that one of the most common corridors of access for drainage of sellar cystic craniopharyngiomas is the endoscopic transnasal transsphenoidal route, drainage from the craniopharyngioma cyst into the sphenoid sinus and on to the postnasal space appeared to be a promising route. However, to maintain patency of this route, in contrast to transsphenoidal pituitary surgery, the sellar opening would not be closed or reconstructed after cyst drainage.

Within the setting of endoscopic transnasal transsphenoidal surgery of the skull base, the Hadad-Bassagasteguy pedicled nasoseptal flap has commonly been used to prevent or address CSF leaks within this region. ${ }^{11}$ Herein we propose a novel application for this pedicled mucosal flap, using it to line an area of craniopharyngioma cyst wall epithelium, with the aim of creating a fistula between the 2 epithelial surfaces.

The fistula created between the epithelium of the craniopharyngioma cyst cavity and the epithelium of the nasoseptal flap would allow persistent drainage of the cyst fluid out of the craniopharyngioma cyst, into the sphenoid sinus, and on to the postnasal space. However, the flap would need to be placed in such a manner as not to occlude the sphenoidotomy, sellar opening, and durotomy, and allow these apertures to remain open, thus providing a permanent drainage pathway and preventing cystic reaccumulation and its sequelae (Fig. 1).

\section{Methods}

\section{Study Design and Patient Selection}

We carried out a retrospective observational review of 3 cases involving male patients with recurrent cystic subdiaphragmatic craniopharyngioma, aged 8, 22, and 45

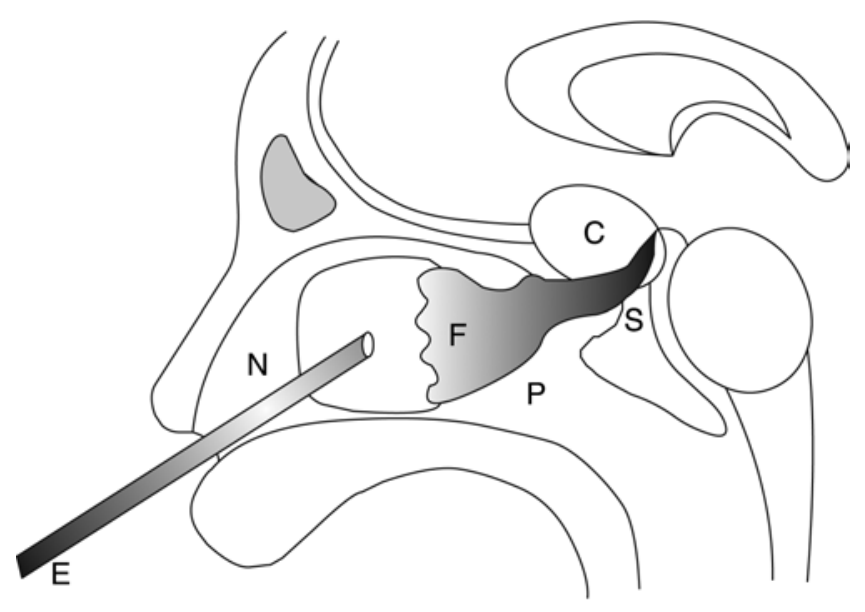

FIG. 1. An illustration showing the sagittal view of the ETEF approach. $\mathrm{C}=$ craniopharyngioma cyst; $\mathrm{E}=$ endoscope; $\mathrm{F}=$ nasoseptal flap; $\mathrm{N}=$ nasal cavity; $P=$ postnasal space; $S=$ sphenoid bone. Copyright Sandeep P. Solanki. Published with permission.

years at the time of undergoing endoscopic transnasal external fistulation (ETEF) between 1998 and 2014. All patients had previously undergone 1 or more established procedures (craniotomy and resection plus radiotherapy; microscopic transsphenoidal resection, endoscopic transsphenoidal drainage) to address predominant cystic craniopharyngioma of the sellar region at the Queen's Medical Centre, Nottingham, UK (Table 1).

\section{Preoperative Assessment}

All patients received thorough endocrinological and ophthalmological review and optimization prior to surgery. Tumors were characterized by a neuroradiologist using contrast-enhanced MRI, and suitability for the ETEF procedure was determined by a neurosurgeon in conjunction with a rhinologist/endoscopic skull base surgeon.

\section{Outcome Measures}

Our main outcome measure was sustained cyst involution on follow-up MRI studies. Operative and postoperative complications together with neurological, endocrinological, and ophthalmological changes were sought from patient notes.

\section{The ETEF Technique}

The ETEF procedure is performed under a general anesthetic, and the nasal cavity is prepared with cocaine and adrenaline soaked cottonoids. The patient is positioned supine, with the head supported in a neutral position.

Using a 2-surgeon, 4-handed technique and the endoscopic transnasal transsphenoidal approach, the middle turbinates are lateralized to improve access and instrumentation. The sphenoid ostia are identified. A unilateral nasoseptal flap is raised upon the nasoseptal branch of the posterior septal artery, and placed aside for later use. Posterior septectomy is then performed, allowing for a wide sphenoidotomy. Mucosectomy is performed within the sphenoid sinus, followed by opening of the sella (Fig. 2).

A durotomy is performed and the cystic craniopharyn- 
TABLE 1. Summary of patients' demographic and clinical characteristics

\begin{tabular}{cccccc}
\hline Case No. & Age (yrs) at ETEF, Sex & Pre-ETEF Symptoms & Prior Procedure, Yr & Yr of ETEF & FU (mos) \\
\hline 1 & 45, M & $\begin{array}{c}\text { Headache, panhypopituitarism, } \\
\text { vomiting }\end{array}$ & TSR, 2003 & 2006 & 96 \\
\hline 2 & 22, M & $\begin{array}{c}\text { Headache, panhypopituitarism, } \\
\text { visual field defect, DI }\end{array}$ & $\begin{array}{c}\text { PtCD, 1998; TSD, RT, 1998; } \\
\text { TSD, 2005; ED, 2006 }\end{array}$ & 2008 & 72 \\
\hline 3 & 8, M & Headache, panhypopituitarism, DI & ED \& RT, 2008 & 2009 & 60 \\
\hline
\end{tabular}

$\mathrm{ED}=$ endoscopic transnasal transsphenoidal drainage; $\mathrm{FU}=$ follow-up; $\mathrm{PtCD}=$ pterional craniotomy \& drainage; $\mathrm{RT}=$ radiotherapy; TSD = microscopic transsphenoidal drainage; TSR = microscopic transsphenoidal resection.

gioma is identified. The cyst wall is incised, and a wide opening is fashioned to drain its contents and allow decompression. Any solid areas in mixed lesions are also debulked. Once fully decompressed, the pedicled nasoseptal flap raised earlier is reflected through the sphenoid and sellar openings and placed inside the cyst cavity, lining the floor of the cyst capsule (the entire fenestration is not circumferentially lined with the flap due to the risk of occluding the opening). This initiates the fistulation process between the cyst wall epithelium and the nasoseptal mucosal epithelium. A silastic splint wrapped around a NasoPore core is placed within the fenestration to maintain patency of the drainage corridor while the fistulation process ensues. This splint combination remains in situ for 2 weeks and is then removed. The sellar opening and sphenoidotomy must be left open for there to remain a persistent drainage pathway for the effluent. Hence, this technique involves no sellar reconstruction. Additional splints
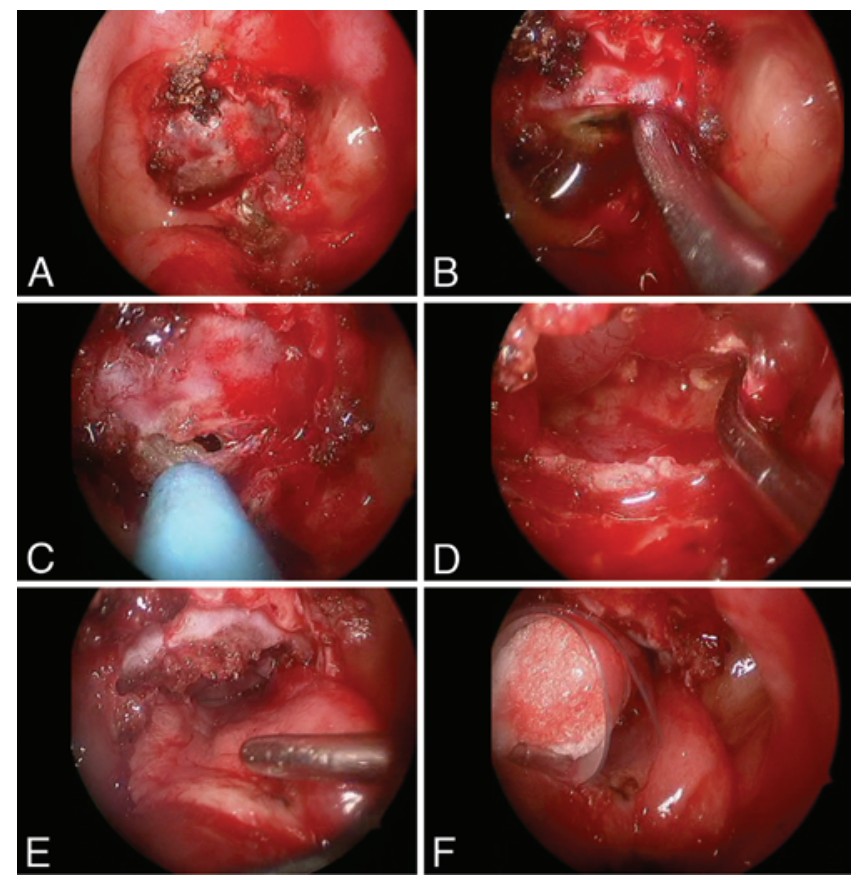

FIG. 2. Intraoperative photographs of key stages in the ETEF procedure via the endoscopic transnasal transsphenoidal route showing the sellar opening (A), durotomy, capsulotomy, cyst drainage (B), removal of solid craniopharyngioma components (C), cyst cavity clearing in preparation to receive the nasoseptal flap (D), nasoseptal flap placement over inferior cyst wall epithelium, initiating the fistulation process (E), and the placement of a temporary silastic splint through the cyst wall aperture to encourage patency of the drainage pathway $(F)$. are applied to the nasal septum, and the nasal cavity is packed for 48 hours.

\section{Postoperative Management}

Patients were monitored for neurological compromise and electrolyte disturbances. The preoperative hormone replacement regimen devised by the endocrinologists continued into the postoperative phase. Twenty-four-hour fluid balance, daily serum and urinary sodium, and osmolalities were used to identify and treat diabetes insipidus (DI). Nasal packs were removed 48 hours postoperatively, and patients were advised not to blow their nose.

\section{Follow-Up Care}

Two-weeks postoperatively, patients were seen in the rhinology outpatient clinic, where all nasal splints were removed, nasoendoscopy was performed, and nasal douching was instructed. An MRI was performed within 3 months, then annually, and patients were reviewed routinely within the neurosurgical, endocrine, and ophthalmology clinics. Pediatric patients also received neuropsychology follow-up.

\section{Results}

Between June 2006 and May 2009, 3 male patients with a mean age of 25 years (8-45 years) underwent the ETEF procedure for recurrent cystic subdiaphragmatic craniopharyngioma. Each patient had 1 or more prior surgical attempts at addressing the lesion (Table 1). Two patients received radiotherapy after their initial surgery due to clinicoradiological disease progression. One patient did not receive radiotherapy, as the oncological perspective deemed the tumor to be predominantly cystic and symptomatic relief with stable disease was achieved after the first procedure. Stable disease was sustained for 3 years in this patient prior to performing ETEF. No radiotherapy was administered post-ETEF in this patient due to quiescent disease and no solid tumor expansion.

Preoperative MRI revealed predominantly cystic subdiaphragmatic craniopharyngioma. In all 3 cases, postoperative imaging revealed complete resolution of the cystic lesion, and this was sustained on subsequent imaging for a mean follow-up of 76 months, ranging from 60-96 months (Fig. 3). Follow-up nasoendoscopy at 4-6 weeks postoperatively revealed patent fenestrations for all 3 patients. Further nasoendoscopy at 3 months for Patient 3 and 2 years (longest endoscopic follow-up) for Patient 2 confirmed patent fenestrations. At 4 -weeks postoperative- 

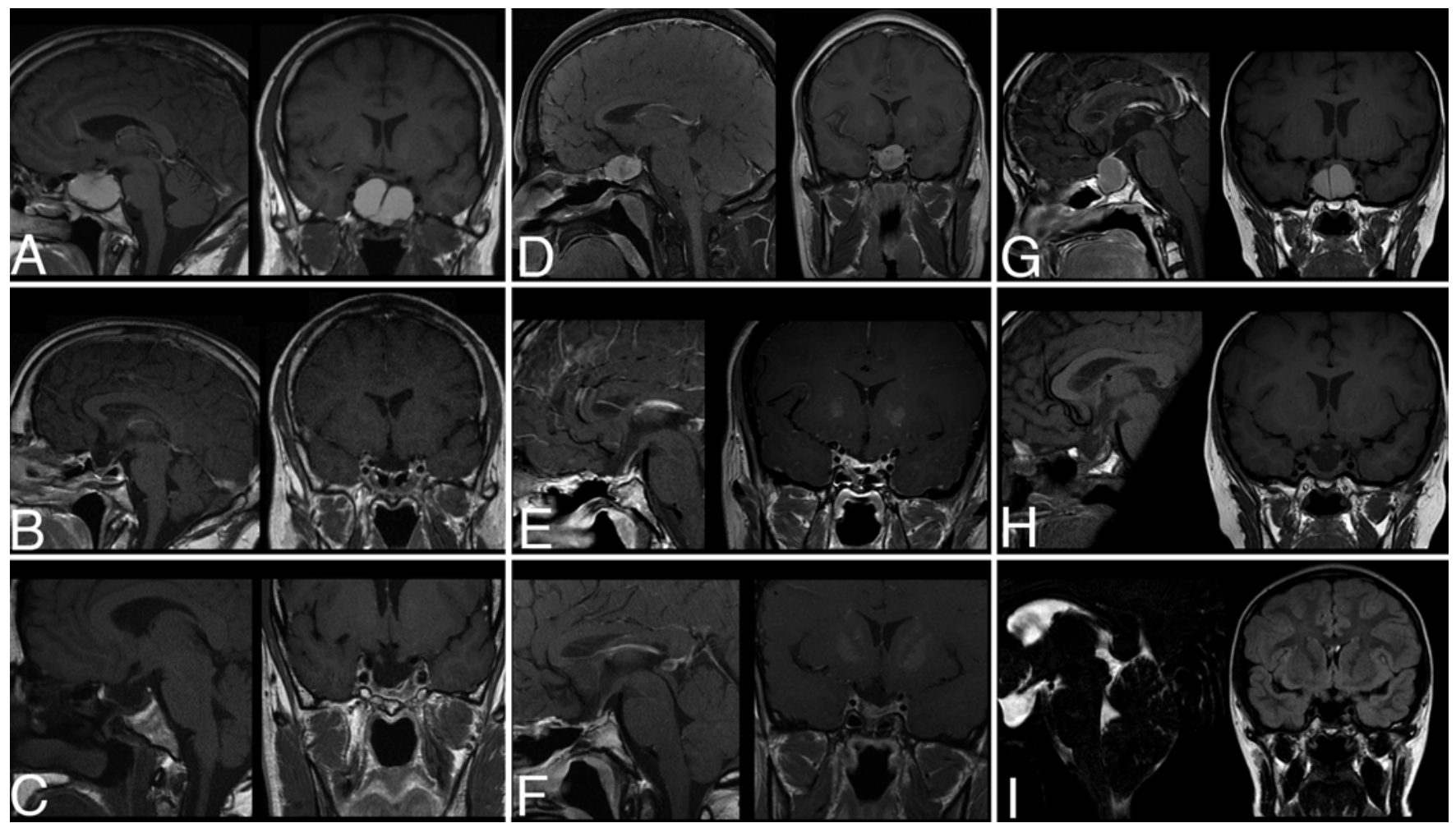

FIG. 3. Pre-ETEF, post-ETEF, and most recent post-ETEF follow-up sagittal (left) and coronal (right) MR images obtained in all 3 patients. Preoperative (A) and postoperative (B) Gd-enhanced and 8 years postoperative (C) unenhanced T1-weighted MR images obtained in Case 1 (45-year-old male). Preoperative (D), postoperative (E), and 6 years postoperative (F) T1-weighted Gdenhanced MR images obtained in Case 2 (22-year-old male). Preoperative (G) Gd-enhanced and postoperative (H) unenhanced T1-weighted MR images and 5 years postoperative (I) CISS sequence (left) and FLAIR image (right) in Case 3 (8-year-old male). Postcontrast sagittal and coronal images for $\mathrm{C}, \mathrm{H}$, and I were not available.

ly for Patient 1, Fig. 4 demonstrates a patent fenestration, with the nasoseptal flap within the cyst cavity in continuity with the cyst epithelium and visible cyst effluent.

The incidence of CSF leak, meningitis, or cerebral abscess formation was $0 \%$. Neurological deficits were not encountered by any patient. All 3 patients suffered from panhypopituitarism from the outset; they continued to receive hormone replacement therapy post-ETEF. Two patients had a continuation of DI that manifested after previous procedures.

Visual field defects were present in all patients upon initial diagnosis of craniopharyngioma. In 2 patients, this had improved after procedures prior to ETEF. A persistent small temporal scotoma in 1 of the patients did not change after ETEF. Symptoms of headache gradually improved in all patients postoperatively.

\section{Discussion}

The use of the endoscopic transnasal transsphenoidal technique is well established in the management of craniopharyngioma. . $, 5,8,26$ Wide angled, superior views together with a binasal approach allowing a 4-handed technique permit resections equivalent to that of an open approach, without the increase in morbidity. Prior to the widespread use of endoscopy, the microscopic transsphenoidal route in the management of craniopharyngioma re- mained a longstanding successful alternative to traditional craniotomy in selected cases. ${ }^{13}$

Despite the advantages of the endoscopic technique, achieving complete resection remains a challenge due to the intimate relationship of this tumor with critical structures such as the hypothalamus, pituitary, optic nerves, and cerebral vasculature. Recurrence of these lesions, therefore, remains a problem.

Although craniopharyngioma is considered a benign lesion, its behavior can appear malignant. The adverse, potentially reversible sequelae of this lesion arise due to the mass effect it exerts. Therefore, resection, whether complete or subtotal, together with cyst decompression can provide relief of symptoms, albeit transient in some cases.

Indeed, removing tumor tissue will reduce both mass effect and further production of cyst fluid and help to prevent cyst expansion. However, any residual tumor capsule also remains capable of secretion and subsequent cystic growth.

In the context of recurrent cystic subdiaphragmatic craniopharyngioma, our technique is focused less on achieving complete curative resection and more on striving for disease control. The ETEF procedure allows safe cyst decompression and also the creation of a persistent drainage pathway for cyst fluid, thus preventing reaccumulation. Such a technique circumvents the need to achieve total capsular clearance and, hence, avoids the inherent risks. 


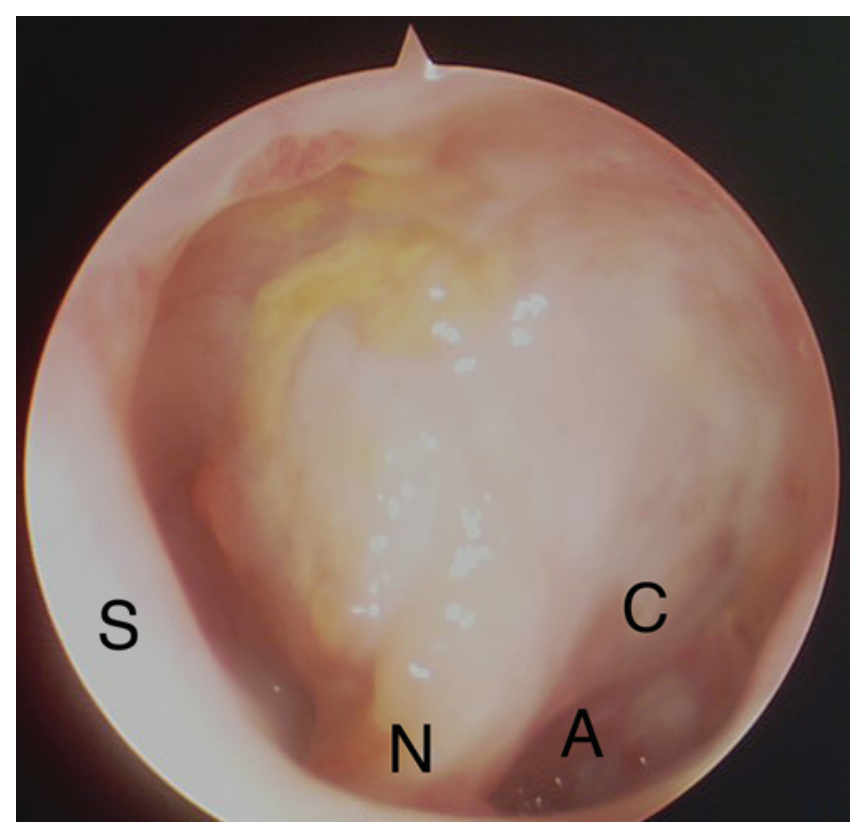

FIG. 4. Nasoendoscopy image obtained in Case 1, 4 weeks post-ETEF. The nasoseptal flap traverses the sphenoid sinus to enter the cyst cavity and lies in continuity with the epithelium of the cyst capsule. Yellow cyst effluent can be seen. $A=$ cyst cavity; $C$ = cyst epithelium; $N$ = nasoseptal flap; $\mathrm{S}=$ sphenoidotomy. Figure is available in color online only.

A similar technique using the microscopic transsphenoidal route to fenestrate the cyst and maintain cyst patency with a silastic splint alone has, however, been previously described..$^{13}$ What is novel about ETEF is the use of the pedicled nasoseptal flap to not only maintain patency of the fenestration but to create a true fistula. Such a communication between the nasal epithelium and cyst capsule epithelium using the nasoseptal flap results in a persistent epithelialized drainage route from cyst to the postnasal space.

Additionally, the use of the pedicled nasoseptal flap for the same purposes of providing a persistent drainage pathway has also been described in the context of endoscopic drainage of cholesterol granulomas of the petrous apex. ${ }^{24}$

Our experience of using this technique in the management of craniopharyngioma within this small series of 3 patients reveals that prevention of cystic recurrence can be effective for up to 8 years after ETEF. We acknowledge that follow-up in the longer term is required, as although recurrence usually occurs within the first few years after surgery, it has been known to occur decades later. ${ }^{9}$ Indeed, all 3 patients who underwent ETEF had undergone numerous prior attempts at addressing the cystic lesion, each subsequently manifesting further recurrence. Follow-up nasaoendoscopy in all 3 patients revealed a patent cyst fenestration with integration of the nasoseptal flap and continuity of cyst and nasal mucosa (Fig. 4). We hence postulate the absence of cystic recurrence to be attributed to an epithelialized drainage pathway from cyst cavity to the postnasal space. Although imaging reveals sustained collapse of cyst cavities for up to 8 years, our longest endoscopic follow-up confirming patency of fenestration was only 2 years. Therefore, an alternate mechanism for long-term cyst involution may be that the maintenance of fenestration patency by the nasoseptal flap allows enough time for the walls of the cyst to collapse down and fuse together, thereby preventing further recurrence.

The main indication for ETEF in our series was an enlarging cystic recurrence of craniopharyngioma, giving rise to symptoms of raised intracranial pressure. Visual compromise was not a key feature. Our results show sustained symptomatic relief from headaches but no change in endocrinological outcome. The efficacy of ETEF in addressing visual compromise remains to be determined.

Within our series, potential adverse complications such as hemorrhage, CSF leak, intracranial sepsis, or new neurological deficit were not encountered. However, as the series expands, such complications may indeed arise. CSF leak is a well-recognized complication of similar endoscopic transsphenoidal procedures, and repair by means of utilizing the same pedicled nasoseptal flap as that used in ETEF is well established..$^{15}$ Consequently, ETEF is contraindicated in the context of CSF leak, as this would result in a persistent CSF fistula and CSF rhinorrhea. CSF leaks during ETEF can be avoided by limiting the procedure to the subdiaphragmatic group of cystic recurrences. If from preoperative imaging it appears unlikely to be feasible to enter the craniopharyngioma cyst without traversing the leptomeninges, ETEF should be avoided. Bilateral pedicled nasoseptal flaps have been widely used in the reconstruction of large skull base defects. ${ }^{11}$ Hence, the use of a single flap to address CSF leak and a second to perform ETEF in this situation remains theoretically plausible, but yet to be elucidated.

A recent pediatric series involving the use of nasoseptal flaps revealed success for a variety of indications in patients ranging from age 5 to 17 years. ${ }^{10}$ The ETEF technique in our study has been performed in patients representative of both adult and pediatric groups (ages 8, 22 , and 45 years), and it remains theoretically feasible in younger children, where endoscopic instrumentation is physically possible and a nasoseptal flap can be raised.

\section{Conclusions}

The use of established endoscopic transnasal transsphenoidal techniques, augmented by the expertise of both rhinologist and neurosurgeon, has resulted in the early success of ETEF. The creation of a fistula between the nasal epithelium and the craniopharyngioma cyst wall epithelium to create a persistent drainage pathway is a novel concept, resulting in nasalization of cystic recurrences. Thus far, ETEF appears to be a safe, effective, and definitive means of achieving disease control in patients with recurrent cystic subdiaphragmatic craniopharyngioma.

\section{Acknowledgments}

We would like to thank Dr. Anish Amlani for his assistance with some of the initial data collection.

\section{References}

1. Adamson TE, Wiestler OD, Kleihues P, Yaşargil MG: Correlation of clinical and pathological features in surgically treated craniopharyngiomas. J Neurosurg 73:12-17, 1990 
2. Barkhoudarian G, Laws ER: Craniopharyngioma: history. Pituitary 16:1-8, 2013

3. Catapano D, Sloffer CA, Frank G, Pasquini E, D’Angelo VA Lanzino G: Comparison between the microscope and endoscope in the direct endonasal extended transsphenoidal approach: anatomical study. J Neurosurg 104:419-425, 2006

4. Cavallo LM, Solari D, Esposito F, Cappabianca P: The endoscopic endonasal approach for the management of craniopharyngiomas involving the third ventricle. Neurosurg Rev 36:27-38, 2013

5. Chakrabarti I, Amar AP, Couldwell W, Weiss MH: Longterm neurological, visual, and endocrine outcomes following transnasal resection of craniopharyngioma. J Neurosurg 102:650-657, 2005

6. Clark AJ, Cage TA, Aranda D, Parsa AT, Sun PP, Auguste KI, et al: A systematic review of the results of surgery and radiotherapy on tumor control for pediatric craniopharyngioma. Childs Nerv Syst 29:231-238, 2013

7. Dastoli PA, Nicácio JM, Silva NS, Capellano AM, Toledo SR, Ierardi D, et al: Cystic craniopharyngioma: intratumoral chemotherapy with alpha interferon. Arq Neuropsiquiatr 69:50-55, 2011

8. de Divitiis E, Cavallo LM, Cappabianca P, Esposito F: Extended endoscopic endonasal transsphenoidal approach for the removal of suprasellar tumors: Part 2. Neurosurgery 60:46-59, 2007

9. Eldevik OP, Blaivas M, Gabrielsen TO, Hald JK, Chandler WF: Craniopharyngioma: radiologic and histologic findings and recurrence. AJNR Am J Neuroradiol 17:1427-1439, 1996

10. Giannoni CM, Whitehead WE: Use of endoscopic vascularized nasoseptal flap in children. Otolaryngol Head Neck Surg 148:344-346, 2013

11. Hadad G, Bassagasteguy L, Carrau RL, Mataza JC, Kassam A, Snyderman CH, et al: A novel reconstructive technique after endoscopic expanded endonasal approaches: vascular pedicle nasoseptal flap. Laryngoscope 116:1882-1886, 2006

12. Kahn EA, Gosch HH, Seeger JF, Hicks SP: Forty-five years experience with the craniopharyngiomas. Surg Neurol 1:5-12, 1973

13. Laws ER Jr: Transsphenoidal microsurgery in the management of craniopharyngioma. J Neurosurg 52:661-666, 1980

14. Lee M, Kalani MY, Cheshier S, Gibbs IC, Adler JR, Chang SD: Radiation therapy and CyberKnife radiosurgery in the management of craniopharyngiomas. Neurosurg Focus 24(5):E4, 2008

15. Liu JK, Schmidt RF, Choudhry OJ, Shukla PA, Eloy JA: Surgical nuances for nasoseptal flap reconstruction of cranial base defects with high-flow cerebrospinal fluid leaks after endoscopic skull base surgery. Neurosurg Focus 32(6):E7, 2012

16. Moussa AH, Kerasha AA, Mahmoud ME: Surprising outcome of Ommaya reservoir in treating cystic craniopharyngioma: a retrospective study. Br J Neurosurg 27:370-373, 2013

17. Müller HL: Childhood craniopharyngioma. Recent advances in diagnosis, treatment and follow-up. Horm Res 69:193202,2008

18. Niranjan A, Kano H, Mathieu D, Kondziolka D, Flickinger
JC, Lunsford LD: Radiosurgery for craniopharyngioma. Int J Radiat Oncol Biol Phys 78:64-71, 2010

19. Prieto R, Pascual JM, Subhi-Issa I, Jorquera M, Yus M, Martínez R: Predictive factors for craniopharyngioma recurrence: a systematic review and illustrative case report of a rapid recurrence. World Neurosurg 79:733-749, 2013

20. Russell RW, Pennybacker JB: Craniopharyngioma in the elderly. J Neurol Neurosurg Psychiatry 24:1-13, 1961

21. Sartoretti-Schefer S, Wichmann W, Aguzzi A, Valavanis A: MR differentiation of adamantinous and squamous-papillary craniopharyngiomas. AJNR Am J Neuroradiol 18:77-87, 1997

22. Sanford RA, Muhlbauer MS: Craniopharyngioma in children. Neurol Clin 9:453-465, 1991

23. Stamm AC, Vellutini E, Harvey RJ, Nogeira JF Jr, Herman DR: Endoscopic transnasal craniotomy and the resection of craniopharyngioma. Laryngoscope 118:1142-1148, 2008

24. Terranova P, Karligkiotis A, Gallo S, Meloni F, Bignami M, Castelnuovo P: A novel endoscopic technique for long-term patency of cholesterol granulomas of the petrous apex. Laryngoscope 123:2639-2642, 2013

25. Weiner HL, Wisoff JH, Rosenberg ME, Kupersmith MJ, Cohen H, Zagzag D, et al: Craniopharyngiomas: a clinicopathological analysis of factors predictive of recurrence and functional outcome. Neurosurgery 35:1001-1011, 1994

26. Yaşargil MG, Curcic M, Kis M, Siegenthaler G, Teddy PJ, Roth P: Total removal of craniopharyngiomas. Approaches and long-term results in 144 patients. J Neurosurg 73:3-11, 1990

\section{Disclosures}

The authors report no conflict of interest concerning the materials or methods used in this study or the findings specified in this paper.

\section{Author Contributions}

Conception and design: Sama, Robertson. Acquisition of data: Solanki. Analysis and interpretation of data: Solanki. Drafting the article: Solanki. Critically revising the article: Solanki, Robertson. Reviewed submitted version of manuscript: all authors. Approved the final version of the manuscript on behalf of all authors: Solanki. Study supervision: Sama, Robertson.

\section{Supplemental Information}

\section{Previous Presentations}

Interim follow-up results of this work have been presented in abstract form and published in the proceedings of the Society of British Neurological Surgeons Bi-Annual Conference (April 18, 2012, Aberdeen, Scotland, UK) and the World Federation of Skull Base Surgeons' Conference (May 16-19, 2012, Brighton, England, UK).

\section{Correspondence}

Sandeep P. Solanki, Queen's Medical Centre, Department of Neurosurgery, C-floor, West Block, Derby Rd., Nottingham NG7 2UH, United Kingdom. email: ssolanki@ doctors.org.uk. 